\title{
Thermodynamics of Wool Dyeing
}

\author{
Riza Atav
}

Additional information is available at the end of the chapter

http://dx.doi.org/10.5772/51618

\section{Introduction}

The pleasure derived from imparting color to clothing has existed since the time of the earliest civilizations; a world of fashion without color is impossible to imagine. Coloration processes produce the most visible results of all the finishing operations carried out during preparation of textile goods [1]. Dyes are synthetic aromatic compounds which can bring bright and firm color to other materials. It is reported that over 100,000 commercially available dyes exist and more than $7 \times 10^{5}$ metric tons of dyes are produced worldwide annually [2]. When a textile fiber is immersed in a solution of dye under suitable conditions, the fiber becomes colored, the color of the solution decreases and dyeing has occurred [3].

The wool fiber is the hair of the sheep and forms the protecting covering of the animal [4]. Structurally, a wool fiber is an assembly of cuticle and cortical cells held together by the "cell membrane complex" (See Figure 1). The dyeing and diffusion properties of fibers are known as governed by this membranous structure, which is formed predominantly by internal wool lipids [5].

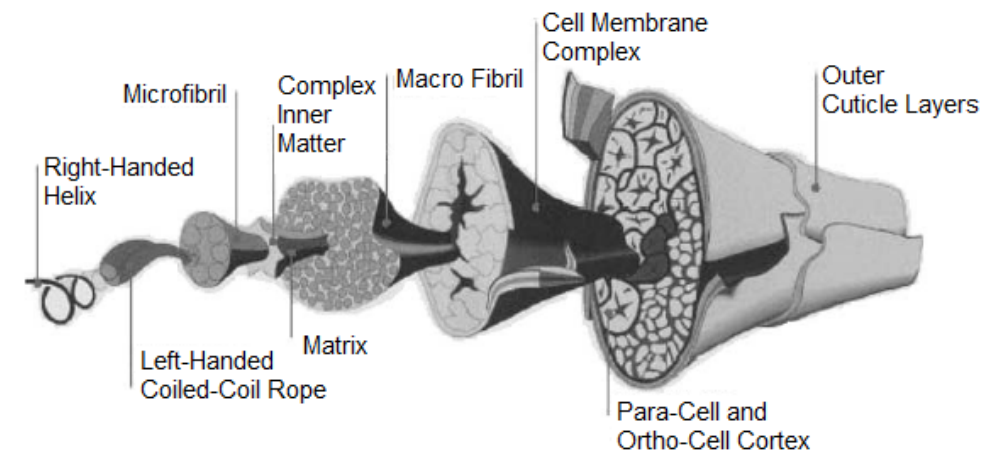

Figure 1. Cross-section diagram of a merino wool fiber [6] 
Wool cuticle cells (overlapping cells that surround the cortex) are subdivided into two main layers, namely the exocuticle and endocuticle [7]. The outer surface of the scale of the cuticle is covered by a very thin membrane called the epicuticle. Below this hydrophobic epicuticle is the exocuticle, a cystine-rich part forming about two-thirds of the scale structure. The exocuticle just below the epicuticle is referred to as the " $\mathrm{A}$ " layer, having a distinctly higher cystine part than the rest of the exocuticle (known as the "B" layer). Below the exocuticle, forming the rest of the scale structure is the endocuticle and then a thin layer of intercellular cement [6].

For wool, its complexity is illustrated by the different important chemical groups it has and the intermolecular forces of attraction that are formed. First, there are the polar peptide groups (i.e., -CO-NH-). Second, the oxygen of the carbonyl groups (-CO-)is slightly negatively charged and, as a result, will form hydrogen bonds with the slightly positively charged hydrogen of the imino groups (-NH-) of other peptide groups. Third, cystine, the sulfur-containing amino acid capable of forming disulfide crosslinking tends towards greater chemical stability, resulting in less dye absorption [8].

Wool dyeing is a process involving high temperature for long periods in acidic to neutral $\mathrm{pH}$ medium to do good penetration, optimum fastness, and dyebath exhaustion. The shape of the conventional dye uptake curve is consistent with an initial dwell time (20 to $40^{\circ} \mathrm{C}$ ) when dye is transported 1 through the medium, a primary exhaustion stage $\left(40\right.$ to $60^{\circ} \mathrm{C}$ ) when dye levels at the fiber surface and diffuses within, and a secondary stage $\left(60\right.$ to $90^{\circ} \mathrm{C}$ and above) during which time the dye disperses and immobilizes within the fiber. There is much resistance to dye penetration from the epicuticle layer of the cuticle cell of the wool [9].

The surface of the cuticle cells is highly hydrophobic due to covalently bound fatty acids. The covalently bound fatty acids and the high amount of disulphide bridges make the outer wool surface highly hydrophobic. Especially in the printing and dyeing of wool, the hydrophobic character of the wool surface is disturbing. Diffusion of the hydrophilic dyes into the fibers is hindered [10].

Earlier workers identified the epicuticle with the barrier to dye penetration, thinking that this part forms a continuous membrane around the fiber. The barrier has also been ascribed to the cuticle and to the highly crosslinked A-layer of the exocuticle. All these suggestions on the nature of the barrier were based on a common belief that dyes must diffuse through the cuticle cells to reach the fiber cortex (i.e. the transcellular route shown in Figure 2) [11]. A continuous phase of membrane cells, the cell membrane complex underneath the cuticle, forms a network of penetrating canals to help mediate the impedance of the lipid barrier to dye diffusion, thereby facilitating dye penetration into the fiber interior [9].

In the manufacture of the almost infinite variety of wool textures, the dyeing of the wool itself is one of the series of many operations involved; and whilst of cardinal importance, the dyeing process must be subordinated to the particular final texture devised by the manufacturer [13]. For dyeing of wool fibers acid, metal complex 1:1 and 1:2, chrome 


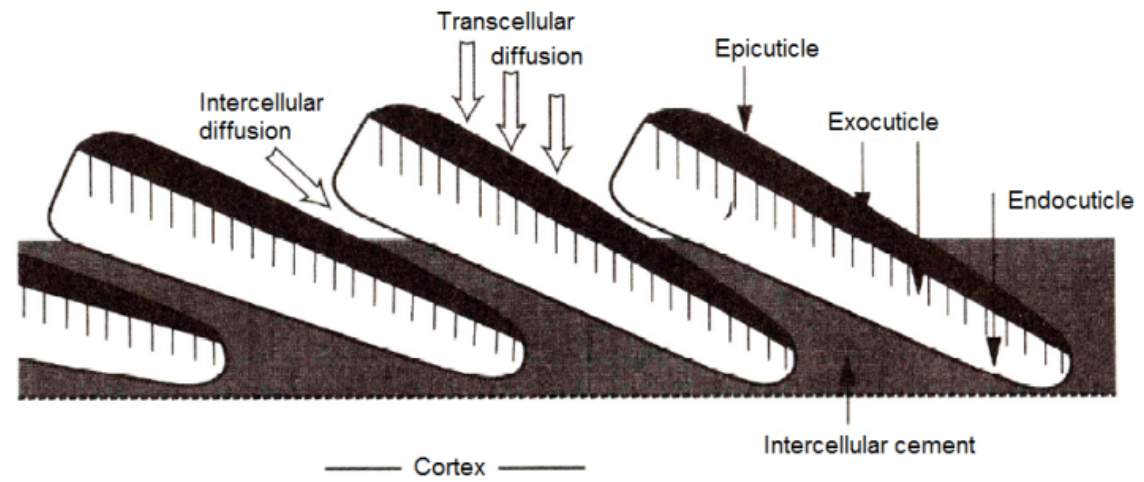

Figure 2. Diffusion pathways for dyes into wool [12]

and reactive dyes can be used [14]. In this chapter knowledge related to the thermodynamics of wool dyeing will be given.

\section{Thermodynamics of wool dyeing}

Dyeing systems can be classified as follows;

1. Non-ionic dyes applied to substrates which are non-ionic or ionic

a. Disperse dyes on essentially non-ionic substrates, such as the hydrophobic fibers produced from polyester, secondary cellulose acetate and cellulose triacetate, and

b. Disperse dyes on ionic substrates such as nylon.

2. Ionic dyes applied to substrates which themselves carry a charge

a. Ionic dyes applied to substrates which carry the same charge as the dye, as exemplified by anionic dyes on cellulose, and

b. Ionic dyes applied to substrates which carry the opposite charge as the dye, such as anionic dyes on wool and nylon and cationic dyes on acrylic fibers [3].

From above classification, it can be understood that the wool dyeing is a good example for dyeing systems described in $2 \mathrm{~b}$. In general, wool dyeing process occurs in four basic steps;

- Wetting and swelling of fibers in dyeing liquor

- Adsorption of dye molecules on the fibers

- Diffusion of dye molecules into the fibers

- Fixation of dye molecules in fibers via various physical and chemical forces [15]

Knowledge in detail related to the thermodynamics of wool dyeing such as aggregation and adsorption of dyes, rate, standard affinity, enthalpy and entropy of dyeing exc. is given below.

\subsection{Aggregation of dyes}

The nature of the dyeing process requires a complete understanding of the state of the dye in the dyebath, and many of the problems associated with the dyeing of wool can be 
explained in terms of the 'colloidal' or aggregated nature of the dye [16]. Aggregation can be defined as "Clustering of each particle of a substance to give it colloidal properties" [1]. A number of organic dyes form aggregates in solution via weak non-covalent interactions. The color, physical properties such as the solubility and photophysical behavior of dyes are affected due to aggregate formation [17]. In dyes, the aggregation principally forms dimers except at high concentrations in solvents with a high dielectric constant. For coloration of materials, it is the monomer adsorbed on the surface. There may be next build up of dye units through aggregation but the first layer must be composed of monomers [18].

Many studies have been carried out on the aggregation of dyes molecules or ions in aqueous and non aqueous solutions. The interactions between dye molecules and other molecular entities are of paramount importance in many industrial processes. The forces of attraction responsible for such interactions are also capable of causing physical interaction between dye molecules to produce molecular species ranging in size from dimmers to aggregates containing hundreds of molecules [19].

The dye aggregation is a function of temperature, electrolyte concentration, surfactant type, and dye concentration [20]. Aggregation is promoted by increasing the concentration of dye in solution [3]. The addition of electrolyte to a dyebath can increase the degree of aggregation, but fortunately the aggregation process is reversible and may be decreased by a rise in temperature. A certain degree of aggregation can be beneficial since it tends to increase the attraction of the dye for the fiber, but the large size of the dye aggregates can lead to a drastic reduction in the rate of fiber penetration, or in some cases to the precipitation (separation) of a dye from solution after prolonged storage [1]. Also chemical structure of dye molecule has an important effect on aggregation. For example; the tetrasulphonated dye C.I. Acid Red 41 has been shown to be monodisperse in aqueous solution by both diffusion-based and light scattering techniques. This result is to be expected, since the four sulphonate groups confer upon this molecule a high degree of hydrophilicity. When the number of sulphonate groups is reduced to one, as in C.I. Acid Red 88, then aggregation is expected to increase. The aggregation of C.I. Acid Red 88 has been determined by diffusion and by polarography at $25^{\circ} \mathrm{C}$, and was found to range between 2 and 5 [16].

So far the changes in absorption spectra have been described qualitatively, yet the aggregation of dyes in aqueous and non-aqueous solutions may be studied quantitatively. The Maximum Slope has proved to be the simplest and the most convenient method to apply for such quantitative study. This method is based on the assumption that a simple equilibrium model between a monomer $(\mathrm{m})$ and polymer $(\mathrm{m}) \mathrm{n}$ is operative [19]:

$$
\mathrm{n}(\mathrm{m}) \leftrightarrow(\mathrm{m}) \mathrm{n}
$$

First the following equation is used to estimate the values for degree of aggregation and aggregation constant:

$$
\log C(\varepsilon 1-\varepsilon)=n \log C\left(\varepsilon-\varepsilon^{\prime} n\right)+\log n K_{n}\left(\varepsilon 1-\varepsilon^{\prime} n\right)^{1-n}
$$


where $\varepsilon_{n}^{\prime}=\varepsilon_{n} / n$

$\varepsilon 1=$ molar absorbativity of monomer

$\varepsilon=$ experimentally measured molar absorptivities

$\varepsilon_{\mathrm{n}}=$ molar absorbativity of polymer

$\mathrm{C}=$ concentration of dye solution in $\mathrm{mol} / \mathrm{L}$

$\mathrm{n}=$ aggregation number

$\mathrm{K}_{\mathrm{n}}=$ aggregation constant

By plotting $\log C(\varepsilon 1-\varepsilon)$ against $\log C\left(\varepsilon-\varepsilon^{\prime} n\right)$, the points should lie on a straight line; the slope of which gives the degree of aggregation (n), and the aggregation constant $\left(K_{n}\right)$ can be calculated from the intercept. Reliable results are very difficult to be obtained due to the assumption one has to make for $\varepsilon_{1}$ and $\varepsilon \mathrm{n}$. The above equation is then rearranged in the form [19]:

$$
1 /(\mathrm{n}-1) \log \mathrm{C}(\varepsilon 1-\varepsilon)-\mathrm{n} /(\mathrm{n}-1) \mathrm{n} \log \mathrm{C}\left(\varepsilon-\varepsilon^{\prime} \mathrm{n}\right)=\log \alpha \mathrm{C}=\mathrm{X}
$$

where $\alpha=(\mathrm{nk})^{1 /(\mathrm{n}-1)}\left(\varepsilon 1-\varepsilon^{\prime} \mathrm{n}\right)^{-1}$

The Maximum Slope Method consists of correlating the curves of $\varepsilon$ vs. $\log C$ and $\varepsilon$ vs. $X$ for different values of $n$ and $\varepsilon_{n}$ until a value of $n$ is reached which gives the best fit between the experimental results and the theoretical curve [19].

\subsection{Adsorption of dyes}

Adsorption is a process that occurs when a gas or liquid solute accumulates on the surface of a solid or a liquid (adsorbent), forming a molecular or atomic film (the adsorbate). It is different from absorption, in which a substance diffuses into a liquid or solid to form a solution. The term sorption encompasses both processes, while desorption is the reverse process [21].

The strength of the adsorption depends on the kind of interactions taking place between the fiber surface and the dye molecules. Clearly, the highest strength results when a chemical interaction occurs. Unfortunately, in many fiber/dye systems such surface interaction cannot be realized. In the case of physical adsorption process, the strength is determined by the Lifshitz - van der Waals, hydrogen bonding, and electrostatic interactions. The nature of the process can be evaluated from the thermodynamic functions of the process [22]. As a result of its chemical structure, wool contains a considerable number of both acidic and basic groups and hence, it was natural to consider that the adsorption of ions by wool was directly concerned with the presence of these groups; this is in turn led to the idea that ions are adsorbed by wool on specific sites in the fiber [3].

Adsorption is usually described through isotherms, that is, functions which connect the amount of adsorbate on the adsorbent, with its pressure (if gas) or concentration (if liquid) 
[21]. The Langmuir isotherm, the Freundlich isotherm, and the Nernst isotherm are all commonly used to classify dyeing isotherms even though they more correctly apply to the adsorption of gases on metal surfaces [16]. Their shapes are shown in Figure 3 [23].

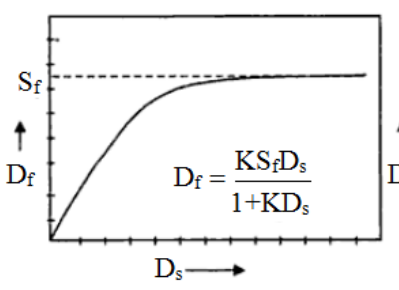

(a) Langmuil

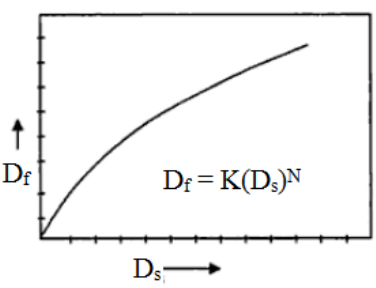

(b) Freundlich

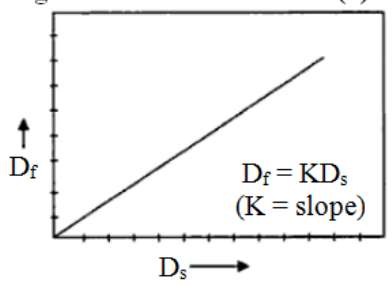

(c) Nernst

Figure 3. Specific isotherms of dye-fiber systems (Ds: Dye concentration in the dyebath, Df: Dye concentration in the fiber) [23]

The simplest physically plausible isotherm is based on three assumptions:

1. Adsorption cannot proceed beyond monolayer coverage.

2. All sites are equivalent and the surface is uniform

3. There are no interactions between adsorbed molecules, so the ability of a molecule to adsorb at a given site is independent of the occupation of neighboring sites [24].

The Langmuir isotherm is well suited to describe dye adsorption by certain textile fibers. Considered in terms of dyeing, the basic postulate is that adsorption of dye takes place on specific sites in the fiber and that when a dye molecule occupies a site that site is saturated and incapable of further adsorption [3]. The Langmuir model is valid for monolayer sorption onto a surface with a finite number of identical sites. Langmuir isotherm theory is based on the assumption that adsorption on a homogeneous surface [25]. On the bases of these assumptions Equation 3 can be written [16]:

$$
\mathrm{C}_{\mathrm{f}, \mathrm{a}}=\mathrm{K}^{\prime} \mathrm{C}_{\mathrm{s}, \mathrm{m}} /\left(1+\mathrm{K}^{\prime} \mathrm{C}_{\mathrm{s}, \mathrm{m}}\right)
$$

$\mathrm{C}_{\mathrm{f}, \mathrm{a}}$ : concentration of adsorbed dye molecules on the fiber

$\mathrm{C}_{\mathrm{s}, \mathrm{m}}$ : concentration of mobile dye molecules in the bath

$\mathrm{K}^{\prime}$ : Adsorption constant

In the case of the Freundlich model (Equation 4) the dye is considered as being contained in an internal phase of volume $\mathrm{V}$ of the fiber. 


$$
\ln [\mathrm{C}]_{\mathrm{f}}=\ln \mathrm{K}_{\mathrm{F}}+\mathrm{x} \times \ln [\mathrm{C}]_{\mathrm{s}}
$$

where: $[\mathrm{C}]_{\mathrm{f}}$ represents the dye concentration in the fiber at equilibrium, in $\mathrm{mol} / \mathrm{kg}$ dry fiber, and $[\mathrm{C}]_{\mathrm{s}}$ represents the dye concentration in solution at equilibrium, in mol/L; $\mathrm{K}_{\mathrm{F}}$ is the equilibrium constant, and $x$ is a sub-unitary power [26]. The Freundlich isotherm is commonly used to describe adsorption characteristics for heterogeneous surface [27]. The Freundlich model assumes a heterogeneous multilayer adsorption surface with sites that have different energies of adsorption which are not equally available [28].

The Nernst adsorption isotherm (Equation 5) is considered as a limit case of Freundlich and Langmuir adsorption isotherms [26].

$$
[\mathrm{C}]_{\mathrm{f}}=\mathrm{K}_{\mathrm{P}} \times[\mathrm{C}]_{\mathrm{s}}
$$

Nernst isotherm equation is a mathematical representation of the distribution law, which states that a dissolved substance, irrespective of its total amount, distributes itself between two layers or phases in a constant concentration ratio, at constant temperature; the ratio, equal to the constant in Equation 5, is referred to as the distribution or partition ratio. Theoretically the law is limited to describing the behavior of dilute solutions [3].

\subsection{Rate of dyeing}

Four steps can be envisaged in the process of dye uptake:

a. diffusion to the fiber surface,

b. transfer across that surface,

c. diffusion within the fiber to appropriate sites, and

d. binding at those sites.

In principle, any of these could be the slowest-and hence the rate determining-step. The theory of the kinetics of wool dyeing has generally been based on the premise that (c) is the rate determining step (diffusion control). Various algebraic expressions have been derived from Fick's laws of diffusion in an attempt to describe experimental dyeing rates. The most common treatment is the "parabolic", rate law, which was originally derived by Hill to explain the diffusion of phosphate and lactate in muscles. If a semi-infinite solid is brought into contact with a liquid containing a diffusible substance at concentration yo, then the total amount diffused across a unit area (A) at time $t$ is given by the following equation:

$$
\mathrm{A}=2 \cdot \mathrm{y}_{0} \cdot\left(\mathrm{D}_{\mathrm{t}} / \pi\right)^{1 / 2}
$$

where D is the diffusion coefficient of the substance in the solid [29]. The calculated diffusion coefficient appears to be exceedingly small when compared with values for other simpler ions and molecules. This may, of course, be due merely to the size of the dye anion, as diffusion within the solid is subject to greater restriction than aqueous diffusion, which suggests that the diffusing unit must force a path through more or less rigidly held molecules, so that a high activation energy is required. The apparently very low mobility of the dye ions may be due to interaction of ions with the fiber in such a way that the majority 
of ions within the fibers are held on specific sites; diffusion proceeds by way of a small fraction of mobile dye ions, thus giving an apparently very low value for diffusion coefficient [30].

The rate of diffusion of a dye in a fiber increases with increase in dyeing temperature. The effect of temperature on the rate of diffusion is given numerically by the activation energy of diffusion (E) according to the relationship shown in Equation 7:

$$
\mathrm{DT}_{\mathrm{T}}=\mathrm{D}_{0} \mathrm{e}^{-\mathrm{E} / \mathrm{RT}}
$$

Where $\mathrm{D}_{\text {т }}$ is the observed diffusion coefficient at absolute temperature $\mathrm{T}, \mathrm{D}_{0}$ is a constant and $\mathrm{R}$ is gas constant. Hence, if the logarithm of the observed diffusion coefficient is plotted against the reciprocal of $\mathrm{T}$, a straight line of slope $\mathrm{E} / \mathrm{R}$ should be obtained; from which $\mathrm{E}$ can be calculated [23].

Time of half-dyeing ( $\left.\mathrm{t}_{1 / 2}\right)$ is the time taken for a fiber to adsorb $50 \%$ of the dye it would adsorb at equilibrium. It provides an indirect measure of rate of diffusion and is useful for comparing the behavior of dyes applied under identical conditions. Because of the very gradual approach to equilibrium, the time taken to reach equilibrium cannot be measured accurately. However, equilibrium adsorption, $\mathrm{C}_{\alpha}$ can be estimated readily by dyeing for a prolonged period and $t_{1 / 2}$ is then determined using a graph of exhaustion versus time of dyeing at $\mathrm{C}_{\mathrm{t}}=0.5 \mathrm{C}_{\alpha}$ (Figure 4 ). In certain cases, it is preferable to plot exhaustion against logt since then the relevant portion tends to be a straight line and a more accurate estimate of $t_{1 / 2}$ can be obtained [23].

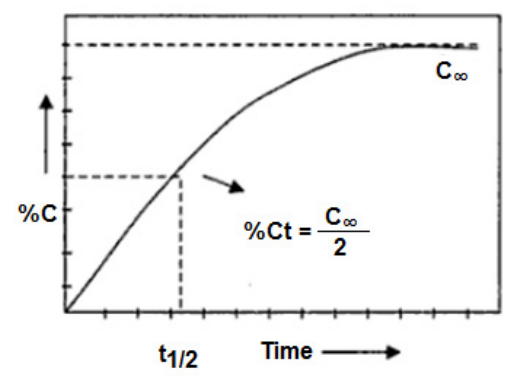

Figure 4. Exhaustion of dyes (\%C) with time [23]

In practice, the experimental conditions must be chosen with care. If the conditions are such that the bulk of the dye is adsorbed on to the surface of the fibers quickly this will musk the effect of diffusion into the fiber [23,31]. The conditions should be so chosen that the dyefiber attraction is low and the final exhaustion is not very high $(<80 \%)$. The time of half dyeing is also very dependent on the amount of dye used [23].

If the time of half dyeing is known for two different temperature activation energy of diffusion (E) can be calculated from the equation given below [31];

$$
\log \left(\mathrm{t}_{1 / 2}\right)_{323}-\log \left(\mathrm{t}_{1 / 2}\right) 363=\left[\mathrm{E} / 2.3^{*} \mathrm{R}\right] *\left[(363-323) /\left(363^{*} 323\right)\right]
$$




\subsection{The standard affinity of dyeing}

Thermal activation is only the first stage in the dyeing process. The driving force in the transfer of dyes from solution to the fiber is the difference in free energy between the two phases. In other words, the energy needed to compress the dye molecules from their freedom of movement in the solution to the restricted volume within the fiber. This is more conveniently expressed in the form of the chemical potential $(\mu)$ which is defined as the difference in free energy between two phases when a very small quantity of dye is added to the solution, all other variables kept constant. The standard potential is derived from the basic equation, applicable to ideal solution, namely Equation 9:

$$
\mu=\mathrm{A}+\mathrm{RT} \ln \mathrm{C}
$$

where $\mathrm{A}$ is a constant, and $\mathrm{C}$ is the molar concentration [23].

A numerical parameter is needed to describe the behavior of individual dyes at equilibrium (thermodynamics) which is independent of variations in the dyeing conditions. Such a parameter would be standard affinity of the dye. Standard affinity of dyes has been defined as "the difference between the chemical potential of the dye in its standard state on the fiber and the corresponding chemical potential in its standard state in the dyebath" [32].

Affinity $\left(-\Delta \mu^{\circ}\right)$ is measurable according to the principles of thermodynamics and may be expressed in energy unit (kjoules/mole). It is the most basic thermodynamic parameter of the dye in dyeing solution towards fiber substrate. The greater the degree of exhaustion at equilibrium the greater is the affinity [33].

The standard affinity for the distribution of dye between the fiber and dyebath is proportional to the logarithm of the ratio of the absolute activities of the dye in the fiber and dyebath. Since the activity of the dye is assumed to be directly related to its concentration, one can write equation as follows [16];

$$
-\Delta \mu^{0}=R T\left[\operatorname{In}\left([C]_{F} /[C]_{L}\right)\right]
$$

$\Delta \mu^{\circ}:$ standard affinity $\left(\mathrm{J} \mathrm{mol}^{-1}\right)$

$R$ : gas constant $\left(8.317 \mathrm{~J} \mathrm{~K}^{-1} \mathrm{~mol}^{-1}\right)$

$\mathrm{T}$ : absolute temperature $\left({ }^{\circ} \mathrm{K}\right)$

$[C] F$ : concentration of dye on the fiber at equilibrium $(\mathrm{g} / \mathrm{l})$

$[C] L$ : concentration of dye remaining in the dyebath at equilibrium $(\mathrm{g} / \mathrm{l})$

It was this point, where values had to be assigned to activities of the ions in the fiber, that a difference of opinion arose and this led to two different approaches being formulated, namely the Langmuir or Gilbert-Rideal method and the Donnan method. The differences between the two are described pictorially in Figure 5 for a simple, monobasic strong acid HX [3]. 

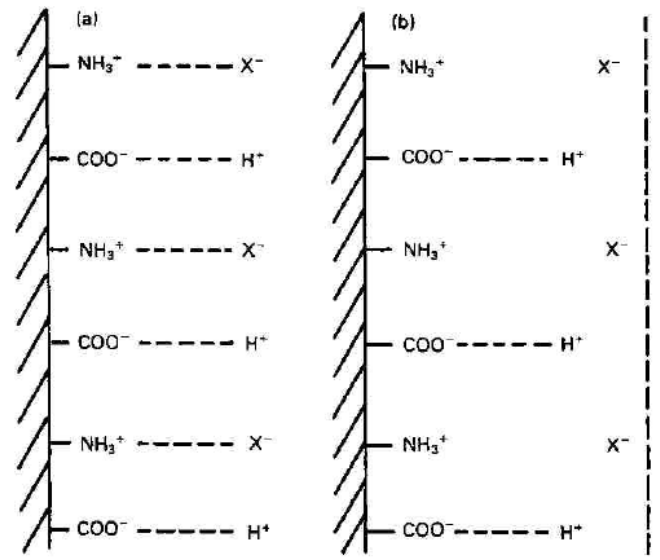

Figure 5. Pictorial representation of two approaches to wool dyeing theory: (a) Gilbert-Rideal, (b) Donnan [3]

a) Gilbert - Rideal theory: In that explanation, the activity coefficients of ions sorbed into the wool phase are reduced due to specific binding with sites on the wool, that is, the formation of ion pairs. Wool dyeing generally occurs in the presence of an acid as well as the dye (the acid is usually applied in a preliminary step). Gilbert and Rideal proposed that dye uptake is an anion exchange process, in which the dye molecules displace smaller anions [29].

b) Donnan theory: In this theory, the dye was considered to partition between the external solution and an internal solution phase in the wool. The latter phase is believed to contain a high concentration of fixed ionic groups, and hence solute molecules have reduced activity coefficients in that phase due to Coulombic interactions [29].

Derbyshire and Peters, proposed a unified interaction theory for all dye-fiber systems, postulating that the principal contribution to the standard affinity of the dyes, of all classical types, to all kinds of fibers arises from the nonpolar Van der Waals forces. They postulated that non-polar forces are mainly responsible for dye-fiber attachment and that in aqueous solution they occur between hydrophobic surfaces. The dyeing behavior of each type of fiber is predicted from the postulate that dye substantivity is due to non-polar forces. They suggested that the hydrophobic parts of the dye molecules have adequate affinity for the hydrophobic parts of the fiber. Accordingly the less hydrophobic dye molecules also have sufficient affinities for the more hydrophobic synthetic fibers, whereas dye molecules with larger hydrophobic parts will be required to dye a hydrophilic fiber such as wool [34].

Zollinger considered hydrophobic bonding in addition to the two well-known types of dyefiber interaction in the adsorption of anionic dyes by wool such as coulombic attraction of dye anions to cationic groups on the fibers and Van der Waals (London) forces. The thermodynamic parameters such as standard enthalpies and standard entropies were measured for the adsorption of three suitable acid dyes on wool, and it was concluded that aliphatic side-chains contributed to the dye-fiber hydrophobic interaction. However, the 
detection of this contribution was difficult, because of the additional effect of dye-dye aggregation equilibria in solution [35].

Iyer et al. carried out a study using three different related acid dyes (Table 1); they calculated the heats and entropies of dyeing. They showed that with increasing hydrocarbon chain length, the affinity of the dye was increased, while the effect of a phenyl group was greater than that of a straight chain of four carbon atoms. It is surprising that the heat evolved on dyeing is decreased as the affinity increases. This is unusual, since higher affinity generally corresponds to larger heat of dyeing [36].

\begin{tabular}{|c|c|c|c|c|}
\hline & $\mathbf{R}$ & $\begin{array}{c}-\Delta \mu^{\circ} \\
\left(\mathrm{kCal} \mathrm{mol}^{-1}\right)\end{array}$ & $\begin{array}{c}-\Delta \mathrm{H}^{0} \\
\left(\mathrm{kCal} \mathrm{mol}{ }^{-1}\right)\end{array}$ & 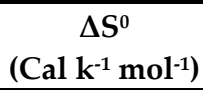 \\
\hline & $-\mathrm{CH}_{3}$ & 5.3 & 7.6 & -7.2 \\
\hline & $-\mathrm{C}_{4} \mathrm{H}_{10}$ & 5.8 & 7.1 & -4.1 \\
\hline & $-\mathrm{C}_{6} \mathrm{H}_{6}$ & 6.0 & 5.6 & +1.2 \\
\hline
\end{tabular}

Table 1. Thermodynamic parameters of acid dyes on wool (at $50^{\circ} \mathrm{C}$ and $\mathrm{pH} 4.6$ ) [36]

The results of the study carried out by Ferrini et al. (Table 2) was also indicated that the phenyl group is more effective in reducing $\Delta \mathrm{H}^{0}$ than is the butyl chain [37]. Asquith et al. claimed that the reason of the effect of a phenyl group to be greater than that of a straight chain was the effect of the phenyl group on dye aggregation to be greater than that of the butyl chain [38].

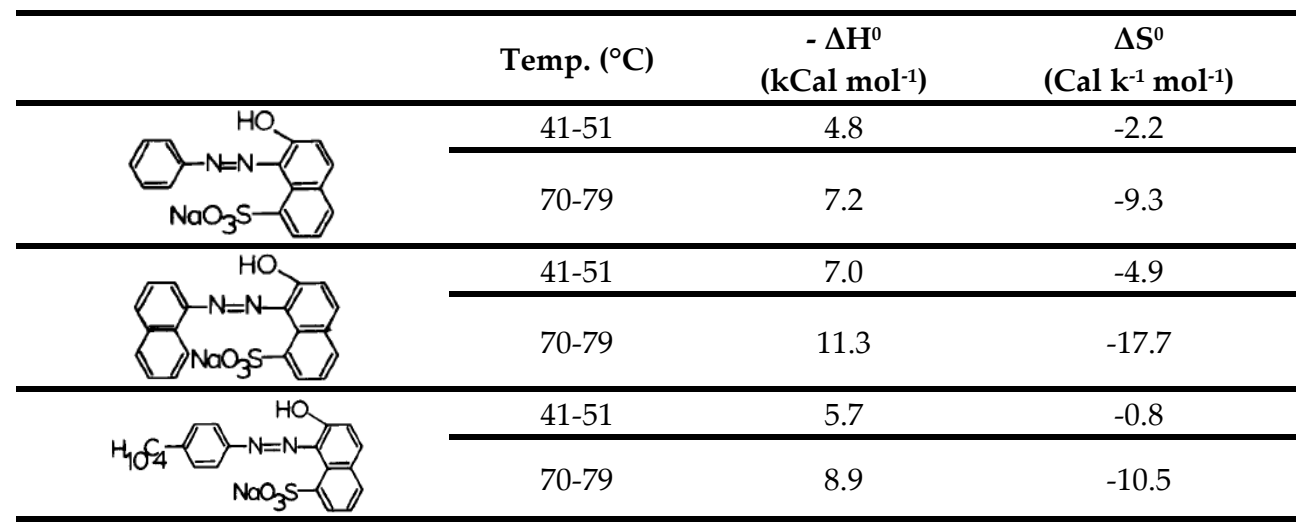

Table 2. Heats of dyeing and entropies of acid dyes on wool [37]

\subsection{The enthalpy of dyeing}

The second thermodynamic quantity which is important in describing a dyeing process is the heat of dyeing or the change in enthalpy of the system when adsorption takes place [3]. As a result of dye molecules to be adsorbed on the fiber surface, free movement of these molecules gets restricted. So that entropy decreases when dye molecule is adsorbed. Adsorption also causes free energy to decrease. 


$$
\Delta \mathrm{G}^{0}=\Delta \mathrm{H}^{0}-\mathrm{T} \cdot \Delta \mathrm{S}^{0}
$$

According to the Equation 11, enthalpy change should be negative, in other words adsorption is exothermic. For this reason adsorption amount will increase, when temperature is decreased [15]. Also the affinity of a dye is dependent on temperature. It decreases as the temperature rises, i.e. the equilibrium shifts in favor of the external phase. When $-\Delta \mu^{\circ} / \mathrm{T}$ is plotted against $1 / \mathrm{T}$ ( $\mathrm{T}$ is the absolute temperature for a particular affinity value), the slope of the straight line obtained gives $\Delta \mathrm{H}^{0}$, the heat of dyeing [39]. However, the numerical value of $\Delta \mu^{\circ}$, obtained from dye absorption, cannot be verified, and $\Delta S^{0}$ is impossible to measure, while $\Delta \mathrm{H}^{0}$ is solely dependent on $\Delta \mu^{\circ}$. Hence, using Equation 5 , any error in $\Delta \mu^{\circ}$ will accumulate in $\Delta \mathrm{H}^{0}$ and $\Delta \mathrm{S}^{0}$. One of the errors in determining $\Delta \mu^{\circ}$ may be due to aggregation of the dye in solution under some conditions. Such an aggregation equilibrium could explain why a linear plot of $-\Delta \mu^{\circ} / \mathrm{T}$ against $1 / \mathrm{T}$ cannot always be obtained. In an attempt to clarify the latter point, Asquith et al. carried out a study on two dyes (C.I. Acid Orange 7 and 10), one known to be non-aggregating under the selected conditions of dyeing studied. Figure 6 shows the plots of $-\Delta \mu^{\circ} / \mathrm{T}$ against $1 / \mathrm{T}$ for these two dyes [38].

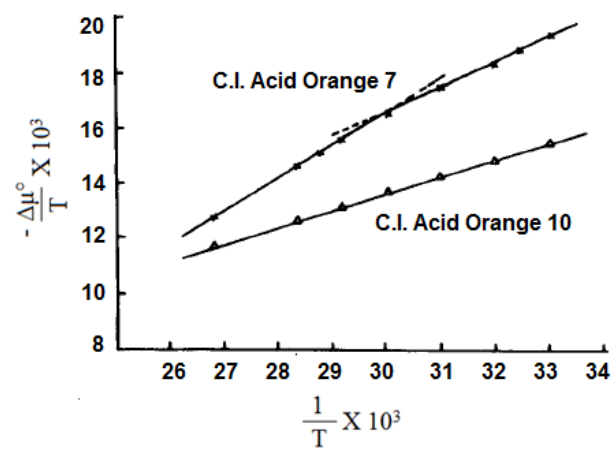

Figure 6. The relationship between $-\Delta \mu^{\circ} / \mathrm{T}$ and $1 / \mathrm{T}$ for various acid dyes [38]

According to these experimental results Asquith et al. denoted that for Orange 7, the plots each consist of two straight lines, intersecting at $60^{\circ} \mathrm{C}$, which clearly indicates that this dye has two $\Delta \mathrm{H}^{0}$ values, corresponding to two temperature ranges-viz, below and above $60^{\circ} \mathrm{C}$. The deviation from linearity in the above plots immediately leads to the speculation that the $\Delta \mu^{\circ}$ and $\Delta \mathrm{H}^{0}$ values obtained from dyeing with Orange 7 has been influenced by dye aggregation equilibria in solution [38].

If the values of $\Delta \mu^{\circ}$ are available for two absolute temperatures $T_{1}$ and $T_{2}$, it is more convenient to use the Equation 12 [39]:

$$
\Delta \mathrm{H}^{0}=\left(\mathrm{T}_{2} \Delta \mu_{1}{ }^{\circ}-\mathrm{T}_{1} \Delta \mu_{2}{ }^{\circ}\right) /\left(\mathrm{T}_{2}-\mathrm{T}_{1}\right)
$$

where $T_{1}$ is the initial dyeing temperature in Kelvin; $T_{2}$, the final dyeing temperature in Kelvin, $\Delta \mu_{1}$, the affinity at $\mathrm{T}_{1}{ }^{\circ} \mathrm{K}$, and $\Delta \mu_{2}$, the affinity at $\mathrm{T}_{2}{ }^{\circ} \mathrm{K}$ [40]. The value of $\Delta \mathrm{H}^{0}$ 
represents the difference in heat content between that needed to free one mole of dye from the solvent, and that required to free the same quantity of adsorbed molecules from the surface or from the interior of the solid by thermal agitation. It is thus the heat of sorption, i.e. the increase in heat content (enthalpy) of the system when the dye is sorbed. Large negative values of $\Delta \mathrm{H}^{0}$, therefore, correspond to high potential affinity [23].

\subsection{The entropy of dyeing}

The third thermodynamic parameter is the standard change in the entropy of the system $\left(\Delta S^{0}\right)$ [3]. The standard entropy of dyeing, $\Delta S^{0}$, can be calculated from the Gibbs equation [26]:

$$
\Delta \mu^{\circ}=\Delta \mathrm{H}^{0}-\mathrm{T} . \Delta \mathrm{S}^{0}
$$

Because there is no direct experimental means of measuring the entropy change, it is necessary to calculate its value from measurements of $\Delta \mu^{\circ}$ and $\Delta \mathrm{H}^{0}$ [3]. According to Boltzman's conception, the entropy is proportional to the probability of the system [26]. The change in entropy $\left(\Delta S^{0}\right)$ represents (on a logarithmic scale) the ratio of probability of sorption $\left(\beta_{1}\right)$ to that of desorption $\left(\beta_{2}\right)$ as shown in Equation 14:

$$
\Delta S^{0}=R \ln \beta_{1}-R \ln \beta_{2}=R \ln \left(\beta_{1} / \beta_{2}\right)
$$

This entropy of sorption is the gain in entropy or disorder of the system when dye is adsorbed [3]. From the dyeing point of view the entropy change is of practical importance especially in two cases, in which either two dyes are compared on a common fiber or one dye is compared on two fibers. Therefore, dyeing entropy can almost be identified with dye/fiber orientation [26].

The entropy changes due to the dye sorption can be evaluated in a similar way to the enthalpies from the sorption isotherms determined at different temperatures via the free energy of adsorption $\Delta \mathrm{G}^{0}$.

$$
\Delta \mathrm{S}_{\mathrm{ad}}^{0}=\mathrm{R}\left(\mathrm{T}_{1} \ln \mathrm{C}_{1}-\mathrm{T}_{2} \ln \mathrm{C}_{2}\right) /\left(\mathrm{T}_{2}-\mathrm{T}_{1}\right)
$$

The change in entropy upon the sorption process consists of two parts, one of which results from the dehydration of dye molecules before their adsorption (and dilution of the solution) and the other is connected with the actual interaction of the molecules with the solid surface. While the latter part is negative (loss of the molecular freedom), the former is positive. During a spontaneous adsorption process, the total entropy change is always positive [22].

\section{Conclusion}

Wool fibers have the most widely usage in the textile sector among the animal fibers and these fibers are dyed with acid, metal complex 1:1 and 1:2, chrome and reactive dyes. In order to understand the dyeing mechanism of these fibers better, it is needed to know thermodynamic and kinetic aspects of the dyeing such as aggregation and adsorption of dyes, rate, standard affinity of dye, enthalpy (standard heat) and entropy of dyeing exc. 


\section{Author details}

Riza Atav

Namık Kemal University, Textile Engineering Department, Tekirdă̆, Turkey

\section{References}

[1] Ingamells W. Colour for Textiles a User's Handbook Society of Dyers and Colourists ISBN 09019565621993

[2] Gong R., Liu Y., Jiang Y., Li C. Isothermal, Kinetic and Thermodynamic Studies on Basic Dye Sorption onto Tartaric Acid Esterified Wheat Straw African Journal of Biotechnology 2009;8(24) 7138-7147.

[3] Johnson A. The Theory of Coloration of Textiles Second Edition Society of Dyers and Colorists 1989

[4] Von Bergen W., Krauss W. Textile Fiber Atlas: A Collextion of Photomicrographs of Common Textile Fibers American Wool Handbook Company New York 1942

[5] Marti M., Barsukov L.I., Fonollosa J., Parra J.L., Sukhanov S.V., Coderch L. Physicochemical Aspects of the Liposome-Wool Interaction in Wool Dyeing Langmuir 2004;20 3068-3073.

[6] Feughelman M. Introduction to the Physical Properties of Wool, Hair and Other $\alpha$ Keratin Fibers in: Mechanical Properties and Structure Of Alpha-Keratin Fibers: Wool, Human Hair and Related Fibers UNSW Press 1997; 1-14.

[7] Silva C.J.S.M., Prabaharan M., Gubitz G., Cavaco-Paulo A. Treatment of wool fibers with subtilisin and subtilisin-PEG Enzyme and Microbial Technology 2005;36 917-922.

[8] Micheal M.N., El-Zaher N.A. Efficiency of Ultraviolet/Ozone Treatments in the Improvement of the Dyeability and Light Fastness of Wool Journal of Applied Polymer Science 2003;90 3668-3675.

[9] Cardamone J.M., Damert W.C. Low-temperature Dyeing of Wool Processed for Shrinkage Control Textile Research Journal 2006;76(1) 78-85.

[10] Onar N., Sarışık M. Use of Enzymes and Chitosan Biopolymer in Wool Dyeing Fibers \& Textiles in Eastern Europe 2005;13(1) 54-59.

[11] Marti M., Parra J.L., Coderch L. Natural Dyes: Chapter 5: Lipid Role in Wool Dyeing Ed. by Akcakoca Kumbasar E.P. InTech ISBN 978-953-307-783-3 2011.

[12] Simmonds D.H. The Amino Acid Composition of Keratins Australian Journal of Biological Sciences 1955;8(4) 537-540.

[13] Horsfall R.S., Lawrie L.G. The Dyeing of Textile Fibers Chapman\&Hall LTD London 1946; 229.

[14] Yurdakul A., Atav R. Principles of Dyeing and Printing Ege University Engineering Faculty Department of Textile Engineering Bornova-Izmir 2006.

[15] Tarakçıoglu I., Textile Dyeing-I Notes, Ege University Engineering Faculty Press Izmir 1979-1980.

[16] Lewis D.M. Wool Dyeing Society of Dyers and Colourists 1992. 
[17] Saha S.K. Dye-aggregation in Solution: Molecular Exciton Model 2010. http://www.scitopics.com/Dye_aggregation_in_solution_Molecular_exciton_model.htm 1 (accessed 22 April 2012)

[18] Walmsley F. Aggregation in Dyes: A Spectrophotemetric Study 1992;69(7) 583.

[19] Alarfaj N.A., El Khiate Z.M., Moussa E.A., Spectrophotometric Studies on Aggregation of Some Acid Dyes in Different Media Journal of King AbdulAziz University Science 2008; 99-110.

[20] Gabriela M.S., Elena G.M., Szabaday Z. Aggregation of Two Direct Dye Derived from 4,4'-Diaminostilbene-2,2'-Disulphonic Acid. Spectroscopic and Mathematical Studies, $14^{\text {th }}$ International Electronic Conference on Synthetic Organic Chemistry, 1-30 November 2010.

[21] http://www.fpharm.uniba.sk/fileadmin/user_upload/english/Physical_Chemistry/5Adsorption.pdf (accessed 25 April 2012)

[22] Espınosa-Jıménez M., Padılla-Weıgand R., Ontıveros-Ortega A., Perea-Carpio R., Ramos-Tejada M. M., Chıbowskı E. Investigation of the Polyamide 6,6 Dyeing Process with Acid Blue 45 dye. Part I. Thermodynamics of Acid Blue 45 Adsorption J. Adhesion Sci. Technol. 2002;16(3) 285-301.

[23] Kumar A., Choudhury R. Textile Preparation and Dyeing Science Publishers-USA ISBN 1-57808-402-4 2006

[24] Atkins P., Paula J. Elements of Physical Chemistry Oxford University Press Fourth edition ISBN: 01992718362005

[25] Tan L.S., Jain K., Rozaini C.A. Adsorption of Textile Dye From Aqueous Solution on Pretreated Mangrove Bark An Agricultural Waste: Equilibrium and Kinetic Studies 2010;5(3) 283-294.

[26] Simu G.M., Funar-Timofei S., Kurunczi L. Influence of Temperature and of the Electrolyte Concentration in the Dyeing Process of a Cellulosic Fiber with a Disazo Direct Dye Buletinul Stiinţific al Universităţii “Politehnica" din Timisoara ROMANIA 2008;53(67) 153-155.

[27] Zawani Z, Luqman Chuah A, Thomas S.Y. Choong Equilibrium, Kinetics and Thermodynamic Studies: Adsorption of Remazol Black 5 on the Palm Kernel Shell Activated Carbon (PKS-AC) European Journal of Scientific Research 2009;37(1) 63-71.

[28] Narayanachar K., Puttaswamya V., Gowdab K.N., Sudhakar R. Extraction of Natural Color Component from The Bark of Belleric Myrobalan (Terminalia Bellerica): Kinetic and Adsorption Studies European Journal of Chemistry 2010:1(3) 206-210.

[29] Bruce R.L., Broadwood N.V., King D.G. Kinetics of Wool Dyeing with Acid Dyes Textile Research Journal 2000; 70(6) 525-531.

[30] Alexander P., Hudson R.F. The Kinetics of Wool Dyeing: Part I: Simple Acid Dyes Textile Research Journal 1950:20 481-491.

[31] Dugg D.G., Sinclair S. Giles's Laboratory Course in Dyeing (Fourth Edition) ISBN-13: 9780901956491 December 1989.

[32] Aspland J.R. Textile Dyeing and Coloration American Association of Textile Chemists and Colorists ISBN 0-9613350-1-7 1997. 
[33] Adebayo G.B, Adekola F.A, Olatunji G.A, Bello I.A. Some Thermodynamic Parameters of Two Indigenous Mineral Dyes Applied on Wool Material Bulletin of Pure and Applied Sciences 2010:29C (2) 77-95.

[34] Derbyshire A.N., Peters R.H. An Explanation of Dyeing Mechanisms in Terms of Nonpolar Bonding J. Soc. Dyers Colour. 1955:71 530-536.

[35] Zollinger H. The Dye and the Substrate: The Role of Hydrophobic Bonding in Dyeing Processes J. Soc. Dyers Colour. 1965;81 345-350.

[36] Iyer S.R.S., Ghanekar A.S., Singh G.S. The Chemistry of Synthetic Dyes Vol. VII Ed. by Venkataraman K. Academic Press New York 1974; 236

[37] Ferrini B., Kimura Y., Zollinger H. A Contribution to the Dyeing Mechanism of Acid Dyes on Wool Proc. Int. Wool Textile Res. Conf. Paris 1965; 291-300.

[38] Asquith R.S., Kwok W.F., Otterburn M.S. An Assessment of Some Thermodynamic Treatments of Wool Dyeing Systems Textile Research Journal 1980;50 333-336.

[39] Kumar A., Choudhury R. Textile Preparation and Dyeing Science Publishers ISBN 157808-402-4 2006.

[40] Samanta A.K., Agarwal P., Datta S., Physico-chemical Studies on Dyeing of Jute and Cotton Fabrics Using Jackfruit Wood Extract: Part II Dyeing Kinetics and Thermodynamic Studies Indian Journal of Fiber\&Textile Research 2008;33 66-72. 